\title{
A Novel Technique Using Ultrasonography in Upper Airway Management After Anterior Cervical Decompression and Fusion
}

\section{Shizumasa Murata}

Wakayama Medical University

Hiroshi Iwasaki ( $\sim$ hiwasaki@wakayama-med.ac.jp )

Wakayama Medical University

Hiroyuki Oka

Wakayama Medical University

Hiroshi Hashizume

Wakayama Medical University

Yasutsugu Yukawa

Wakayama Medical University

Akihito Minamide

Wakayama Medical University

Shunji Tsutsui

Wakayama Medical University

Masanari Takami

Wakayama Medical University

Keiji Nagata

Wakayama Medical University

Ryo Taiji

Wakayama Medical University

Takuhei Kozaki

Wakayama Medical University

Hiroshi Yamada

Wakayama Medical University

\section{Research Article}

Keywords: ultrasonography, anterior cervical decompression and fusion, prevertebral soft tissue, surgery, intensive care units

Posted Date: May 7th, 2021 
DOI: https://doi.org/10.21203/rs.3.rs-493346/v1

License: (c) (1) This work is licensed under a Creative Commons Attribution 4.0 International License. Read Full License

Version of Record: A version of this preprint was published at BMC Medical Imaging on April 12th, 2022. See the published version at https://doi.org/10.1186/s12880-022-00792-8. 


\section{Abstract}

The aim is to describe an ultrasound procedure that evaluates the prevertebral soft tissue (PST) and upper airway and investigate the compatibility between X-ray and ultrasonography in PST evaluation. We included 11 radiculopathy/myelopathy patients who underwent anterior cervical decompression and fusion involving $\mathrm{C} 5 / 6, \mathrm{C6} / 7$, or both segments. The condition of the PST and upper airway was evaluated over 14 days. The Bland-Altman method was used to evaluate the degree of agreement between the PST values obtained using radiography versus ultrasonography. The Pearson correlation coefficient was used to determine the relationship between the PST measurement methods. Single-level anterior cervical decompression and fusion (ACDF) was performed in 8 cases and double-level ACDF, in 3 cases. PST and upper airway thickness peaked on postoperative day 3 , with no airway complications. The Bland-Altman bias was within the prespecified clinically nonsignificant range $-0.13 \pm 0.36 \mathrm{~mm}(95 \% \mathrm{Cl} 0.04-0.22 \mathrm{~mm})$. Ultrasonography effectively captured post-ACDF changes in PST and upper airway thickness and detected airway edema. Ultrasonography can help continuously assess the PST and upper airway as it is simple and has no radiation exposure risk. Therefore, radiography alone is insufficient for post-ACDF detection of airway complications and including ultrasonography may be beneficial.

\section{Introduction}

Airway complications due to the formation of retropharyngeal hematomas or prevertebral soft tissue swelling (PSTS) are the most serious complications following anterior cervical decompression and fusion (ACDF). Airway complications can lead to respiratory distress and airway obstruction, requiring emergency reintubation or tracheostomy. ${ }^{[1,2]}$ They occur in $5-6 \%$ of ACDF cases and most frequently between 24 and 48 hours after surgery. ${ }^{[2-4]}$

Risk factors for postoperative airway complications include the involvement of $>3$ operated segments, intraoperative blood loss $>300 \mathrm{~mL}$, and operation time $>90$ minutes. ${ }^{[5,6]}$ When risk factors are present, surgeons traditionally monitor the condition of the prevertebral soft tissue (PST) by examining cervical spine lateral radiographs taken from postoperative day 1 to day 10. ${ }^{[7,8]}$ However, radiographic evaluation is inconvenient and unsafe as it requires transporting the patient or the portable radiography device and exposes the patient to radiation. ${ }^{[9]}$

These problems could be circumvented using an ultrasound device to evaluate the PST and upper airway after ACDF. Ultrasound can be quickly performed at the bedside, and patients are not exposed to radiation. It allows physicians to safely and accurately carry out various medical procedures ${ }^{[10,11]}$ and to rapidly assess the target anatomy in operating theaters, intensive care units, emergency departments, and even in remote environments.

The use of ultrasound in musculoskeletal medicine has expanded rapidly over the last 2 decades. In the field of soft tissue pathology, diagnostic ultrasound has been widely adopted to monitor synovitis in patients with inflammatory joint disorders, tendinopathy, or traumatic tendon ruptures and to detect intra- 
articular effusions. ${ }^{[12,13]}$ Despite its widespread use and its potential to aid in the early recognition and management of airway complications, ultrasound is not routinely used to examine the PST and upper airway after ACDF.

This report describes an ultrasound procedure for evaluating the condition of the PST and upper airway. We also investigated the compatibility between radiography and ultrasonography in PST evaluation. A representative case and a pilot study are presented.

\section{Methods}

\section{Ultrasound evaluation procedure}

Upper airway ultrasound was performed with the patient in the supine position. No special device was required; a standard ultrasound device (SNiBLE; Konica Minolta, Tokyo, Japan) and high-frequency linear probe (L11-3; Konica Minolta) provided sufficient visualization. We identified the desired cervical spine level and tissue by examining the palpable laryngeal prominence of the thyroid cartilage in the cervical region and the palpable hard and smooth cricoid cartilage on the caudal side, which indicate the height of the 5th and 6th cervical vertebral body, respectively (Fig. 1).

\section{Thyroid cartilage and cricoid cartilage in the transverse plane}

The thyroid cartilage, laryngeal prominence, and cricoid cartilage were palpated in the anterior neck region. The probe was horizontally placed above the thyroid cartilage to visualize the anterior surface in the transverse plane; in the resultant ultrasound image, the thyroid cartilage had a triangular shape (Fig. 2A). The probe was then moved to the caudal side, and an arcuate area of the cricoid cartilage was observed on the caudal side of the cricothyroid ligament (Fig. 2B). By sliding the probe slightly outward, the anterior surface of the vertebral body was confirmed, and the thickness of the PST was evaluated (Fig. 2B). Sliding the probe cranio-caudally allowed detection of the cranio-caudal expansion of the PST.

\section{Cricoid cartilage and tracheal cartilage in the longitudinal plane}

The probe was placed longitudinally in the anterior neck region to visualize the thyroid cartilage and oval cricoid cartilage with acoustic shadows. Sliding the probe caudally allowed for observation of the tracheal cartilage and tracheal surface (Fig. 2C). The boundary between the air in the trachea and the anterior wall of the trachea was linearly hyperechoic.

\section{Patient population of the pilot study}

Eleven patients who underwent ACDF involving 1 or 2 segments (C5/6, C6/7, or both) for the treatment of radiculopathy or myelopathy were prospectively enrolled in this study between January 1 and June 30, 2020. The exclusion criteria included fusions involving >3 segments; previous revision surgery or corpectomy; surgically treated trauma, infections, or tumors; and presence of general metabolic diseases, such as rheumatoid arthritis and diabetes, and chronic heart and renal diseases. 


\section{Ethical statements}

The study protocol was approved by the Research Ethics Committee of Wakayama Medical University. All patient-related procedures performed in this study were in accordance with the ethical standards of the Research Ethics Committee of Wakayama Medical University and the 1964 Declaration of Helsinki and its later amendments. Informed consent was obtained from all participants.

\section{Outcome measurements}

The condition of the PST and upper airway was evaluated consecutively from day 0 (one day before operation) to postoperative day 14 . The thickness of the PST at the C6 vertebral body was first measured on a lateral radiograph of the cervical spine and then in a cross section of the cricoid cartilage on the ultrasound image (Fig. 2B). The thickness of the upper airway was assessed in the longitudinal plane of the cricoid cartilage and tracheal cartilage via ultrasonography (Fig. 2C). To compensate for differences in the physique of the patients, changes in the thickness of the PST and upper airway over time were normalized to the preoperative thickness, referenced as value "1."

\section{Statistical analysis}

The Bland-Altman method was used to evaluate the degree of agreement between the PST values obtained using radiography versus ultrasonography. ${ }^{[14]}$ The $95 \%$ confidence intervals (Cl) between radiography and ultrasonography were calculated; the clinically acceptable limit was set at \pm 1.96 times the standard deviation, which is the upper limit for interscan measurement variability and the threshold

for a clinically significant change. ${ }^{[8,15-18]}$ The Pearson correlation coefficient was used to measure the relationship between the PST values according to the method (radiography versus ultrasonography).

All statistical analyses were performed using JMP version 14 software (SAS Inc., Cary, NC, USA). P values were categorized as follows: $<0.05$, significant; $\geq 0.2$, not significant, and 0.05 to $\leq 0.2$, trending toward significance.

\section{Results}

\section{Demographic data of the patients and outcomes}

The mean age of the 11 patients in our study was 66.5 years (range, 36-82 years) (Table 1). Six patients were men, and 5 were women. Single-level ACDF was performed in 8 cases and double-level ACDF in 3 cases. 
Table 1

Characteristics of the 11 study participants

\begin{tabular}{|ll|}
\hline Age (years) & $\mathbf{6 6 . 5} \pm 16.5$ (range, 36-82) \\
\hline Sex (male:female) & $6: 5$ \\
\hline Number of fusion segments & $1.27 \pm 0.47$ \\
\hline
\end{tabular}

The data are expressed as mean \pm standard deviation.

The mean thickness of the PST (measured via ultrasonography and radiography) and upper airway (measured via ultrasonography) peaked on postoperative day 3 and declined thereafter (Table 2). There were no airway complications in this series. The Bland-Altman bias was $0.13 \pm 0.36 \mathrm{~mm}(95 \% \mathrm{Cl}[0.04$, 0.22]), which is within the prespecified clinically nonsignificant range. Inspection of the Bland-Altman plot (Fig. $3 \mathrm{~A})$ revealed no proportional or systematic errors. The Pearson correlation coefficient $(0.99, \mathrm{p}<$ $0.0001)$ indicated a strong correlation between the PST values obtained via radiography and ultrasonography was (Fig. 3B).

Table 2

Thickness of the prevertebral soft tissue (PST) and airway in the pilot study

\begin{tabular}{|lllllll|}
\hline Thickness $(\mathbf{m m})$ & $\begin{array}{l}\text { Day } \\
\mathbf{0}\end{array}$ & Day $\mathbf{1}$ & Day 3 & Day 5 & Day 7 & Day 14 \\
\hline $\begin{array}{l}\text { PST, } \\
\text { ultrasonography }\end{array}$ & 1 & $\begin{array}{l}1.31 \pm \\
0.16\end{array}$ & $\begin{array}{l}1.70 \pm \\
0.16\end{array}$ & $1.47 \pm 0.15$ & $1.38 \pm 0.16$ & $1.16 \pm 0.13$ \\
PST, radiography & 1 & $130 \pm 0.16$ & $\begin{array}{l}1.70 \pm \\
0.15\end{array}$ & $1.45 \pm 0.15$ & $1.37 \pm 0.15$ & $1.17 \pm 0.14$ \\
& & & & & \\
Airway, radiography & 1 & $\begin{array}{l}1.29 \pm \\
0.16\end{array}$ & $\begin{array}{l}1.71 \pm \\
0.15\end{array}$ & $1.45 \pm 0.16$ & $1.36 \pm 0.14$ & $1.16 \pm 0.12$ \\
\hline
\end{tabular}

The data are expressed as mean \pm standard deviation.

PST; prevertebral soft tissue.

\section{Representative case}

A 36-year-old man presented with right arm pain. Based on radiological tests and the presence of selective nerve root blockage, right $\mathrm{C} 6$ radiculopathy caused by cervical disc herniation was diagnosed. ACDF for $\mathrm{C6} / 7$ cervical disc herniation was performed. Thickness evaluated consecutively from day 0 (one day before operation) to postoperative day 14 via ultrasonography (upper airway) or both lateral radiography of the cervical spine and ultrasonography (PST). The thickness of the PST peaked on day 3 and gradually decreased after day 5 (Fig. 4A), as did the edema of the upper airway (Fig. 4B). Using ultrasound, it was possible to capture an image of the airway edema, which is difficult to evaluate radiographically (Fig. 4B). Lateral radiographs of the cervical spine measured the PST thickness at the C6 vertebral body (Fig. 4C), showing a very similar course to the ultrasound-measured PST. Figure 5 
summarizes the information presented in Fig. 4, showing that ultrasonography (upper airway) or both lateral radiography of the cervical spine and ultrasonography (PST) detected a very similar course.

\section{Discussion}

Airway complications are the most serious complications after ACDF and can have devastating consequences if their detection and intervention are delayed. ${ }^{[1,2]}$ Hence, surgeons must carefully assess the condition of the PST and upper airway by taking lateral radiographs of the cervical spine for several days after surgery. Lateral radiography of the cervical spine has been the mainstay of post-ACDF evaluation. In many hospitals, radiography is routinely used to assess PSTS after ACDF, most commonly by measuring the distance between the anterior margin of the vertebral body and the posterior margin of the airway shadow at the same level. ${ }^{[15,19-22]}$ PSTS has been reported to peak on postoperative day 3 and gradually decrease after day $5 .{ }^{[15,22]}$

Plain radiography is useful for predicting the risk of dyspnea by allowing for the comparison of PST thickness before and after surgery. However, it requires frequent radiation exposure and is inconvenient. $[4,7-9]$ Therefore, we aimed to overcome these problems by using ultrasonography to evaluate the PST and upper airway after ACDF. To our knowledge, this is the first report to present a procedure for doing so. In the representative case and pilot study, ultrasonography captured temporal post-ACDF changes in the thickness of the PST and upper airway as efficiently as radiography but without exposing the patient to radiation. Ultrasonography can also detect airway edema, which is difficult to evaluate radiographically. Collectively, these results suggest that radiography alone is not sufficient for daily post-ACDF inspection of the PST and upper airway and that ultrasonography may be beneficial.

This study has some limitations. First, we were unable to completely replace radiography (the conventional procedure) with ultrasonography because the latter is relatively new, and the data were insufficient for clinical application. To gather enough data, different cervical levels, numbers of surgical segments, and surgical procedures need to be investigated in a larger sample size. Second, like radiographic evaluation, ultrasound evaluation has no index for comparing measured values among patients. Because patients differ in terms of their physique and soft tissue thickness, comparison of their preoperative conditions is necessary. The cut-off value for change between preoperative conditions and postoperative conditions requiring therapeutic intervention (e.g., steroid administration or tracheal intubation) should be clarified in future studies. Third, the experience of the ultrasound operator was not addressed. Future studies should compare the results obtained by different operators with different levels of expertise. Because evaluations are somewhat subjective, calculation of a concordance coefficient for agreement among evaluators, along with a side-by-side radiological evaluation, would be helpful. 
In conclusion, this is the first report to describe a procedure for evaluating the condition of the PST and upper airway via ultrasound. Ultrasonography effectively captured post-ACDF changes in the thickness of the PST and upper airway and detected airway edema. Because it can be performed frequently and easily without radiation exposure, it is extremely useful for careful and continuous assessment of the postoperative condition of the PST and upper airway. We suggest that radiography alone is insufficient for post-ACDF detection of airway complications and that ultrasonography may be beneficial.

\section{Declarations}

\section{Acknowledgements}

The authors wish to thank Ms. Ayaka Shimazaki and Ms. Yukako Hashimoto for their assistance with data reduction and administration. We also thank Ms. Maya Ueda for medical writers.

\section{Author contributions}

Conception and design: H. I.

Acquisition of data: S. M.

Analysis and interpretation of data: H.O. and H. H.

Drafting the article: S. M.

Critically revising the article: H.Y., Y.Y., and A. M.

Review of the manuscript: all authors.

Approval of the final version of the manuscript: all authors.

Statistical analysis: H.O. and K. N.

Administrative/technical/material support: H. Y.

Study supervision: H.Y.

\section{Additional information}

Competing intereststatement: The authors declare no competing interests.

Data availability: The datasets generated during and/or analyzed during the current study are available from the corresponding author on reasonable request

\section{References}


1. Fountas, K. N. et al. Anterior cervical discectomy and fusion associated complications. Spine. 32, 2310-2317 (2007).

2. Sagi, H. C., Beutler, W., Carroll, E. \& Connolly, P. J. Airway complications associated with surgery on the anterior cervical spine. Spine. 27, 949-953 (2002).

3. Epstein, N. E., Hollingsworth, R., Nardi, D. \& Singer, J. Can airway complications following multilevel anterior cervical surgery be avoided? J. Neurosurg. 94, 185-188 (2001).

4. Suk, K. S., Kim, K. T., Lee, S. H. \& Park, S. W. Prevertebral soft tissue swelling after anterior cervical discectomy and fusion. Int. Orthop. 30, 290-294 (2006).

5. Bazaz, R., Lee, M. J. \& Yoo, J. U. Incidence of dysphagia after anterior cervical spine surgery: a prospective study. Spine. 27, 2453-2458 (2002).

6. Kwon, B., Yoo, J. U., Furey, C. G., Rowbottom, J. \& Emery, S. E. Risk factors for delayed extubation after single-stage, multi-level anterior cervical decompression and posterior fusion. J. Spinal Disord. Tech. 19, 389-393 (2006).

7. Andrew, S. A. \& Sidhu, K. S. Airway changes after anterior cervical discectomy and fusion. J. Spinal Disord. Tech. 20, 577-581 (2007).

8. Sanfilippo, J. A. et al. "Normal" prevertebral soft tissue swelling following elective anterior cervical decompression and fusion. J. Spinal Disord. Tech. 19, 399-401 (2006).

9. Omi, H. et al. Protecting surgeons' fingers from radiation exposure during lumbosacral selective nerve root block. Spine Surg. Relat. Res. 3, 178-182 (2018).

10. Bejarano, F., Feeney, A., Wallace, R., Simpson, S. \& Lucas, M. An ultrasonic orthopaedic surgical device based on a cymbal transducer. Ultrasonics. 72, 24-33 (2016).

11. Murata, S., Iwasaki, H., Natsumi, Y., Minagawa, H. \& Yamada, H. Vascular evaluation around the cervical nerve roots during ultrasound-guided cervical nerve root block. Spine Surg. Relat. Res. 4, 1822 (2019).

12. Lento, P. H. \& Primack, S. Advances and utility of diagnostic ultrasound in musculoskeletal medicine. Curr. Rev. Musculoskelet. Med. 1, 24-31 (2008).

13. Patil, P. \& Dasgupta, B. Role of diagnostic ultrasound in the assessment of musculoskeletal diseases. Ther. Adv. Musculoskelet. Dis. 4, 341-355 (2012).

14. Bland, M. \& Altman, D. Statistical methods for assessing agreement between two methods of clinical measurement. Lancet. 327, 307-310 (1986).

15. Song, K. J., Choi, B. W., Kim, H. Y., Jeon, T. S. \& Chang, H. Efficacy of postoperative radiograph for evaluating the prevertebral soft tissue swelling after anterior cervical discectomy and fusion. Clin. Orthop. Surg. 4, 77-82 (2012).

16. Yi, J. L. et al. Perioperative intravenous corticosteroids and radiographic prevertebral soft tissue swelling in anterior cervical fusion for degenerative disease. World Neurosurg. 125, e784-e789 (2019). 
17. Kim, S. W. et al. The natural course of prevertebral soft tissue swelling after anterior cervical spine surgery: how long will it last? Spine J. 17, 1297-1309 (2017).

18. Song, K. J., Choi, B. W., Kim, H. Y., Jeon, T. S. \& Chang, H. Efficacy of postoperative radiograph for evaluating the prevertebral soft tissue swelling after anterior cervical discectomy and fusion. Clin. Orthop. Surg. 4, 77-82 (2012).

19. Chen, M. Y. \& Bohrer, S. P. Radiographic measurement of prevertebral soft tissue thickness on lateral radiographs of the neck. Skeletal Radiol. 28, 444-446 (1999).

20. Duvillard, C., Ballester, M. \& Romanet, P. Traumatic retropharyngeal hematoma: a rare and critical pathology needed for early diagnosis. Eur. Arch. Otorhinolaryngo. 262, 713-715 (2005).

21. Lee, S. H., Kim, K. T., Suk, K. S., Park, K. \& Oh, K. Effect of retropharyngeal steroid on prevertebral soft tissue swelling following anterior cervical discectomy and fusion; a prospective, randomized study. Spine. 36, 2286-2292 (2011).

22. Palumbo, M., Aidlen, J., Daniels, A., Thakur, N. A. \& Caiati, J. Airway compromise due to wound hematoma following anterior cervical spine surgery. Open Orthop. J. 6, 108-113 (2012).

\section{Figures}

A

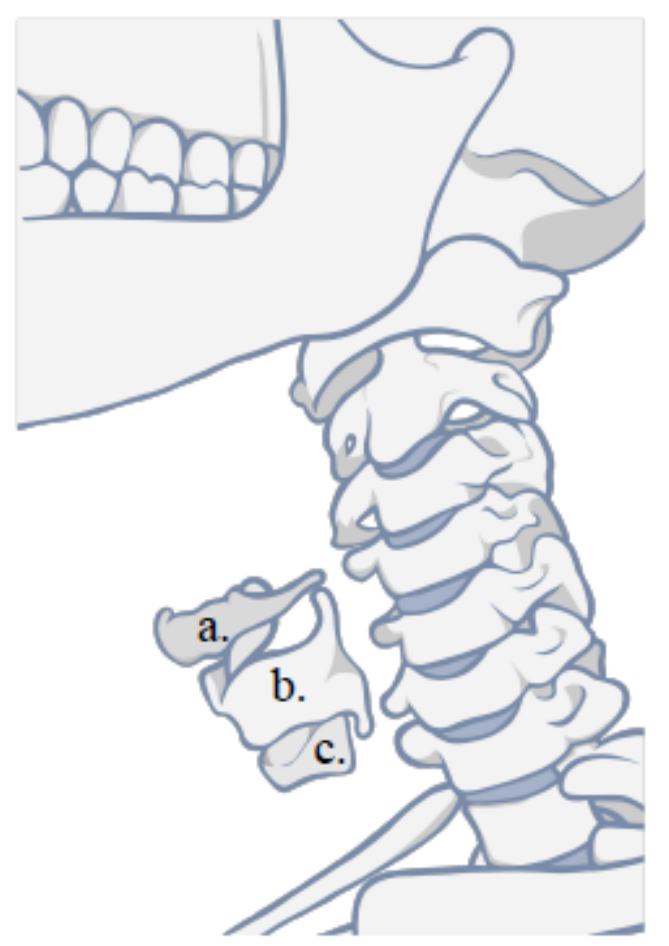

B

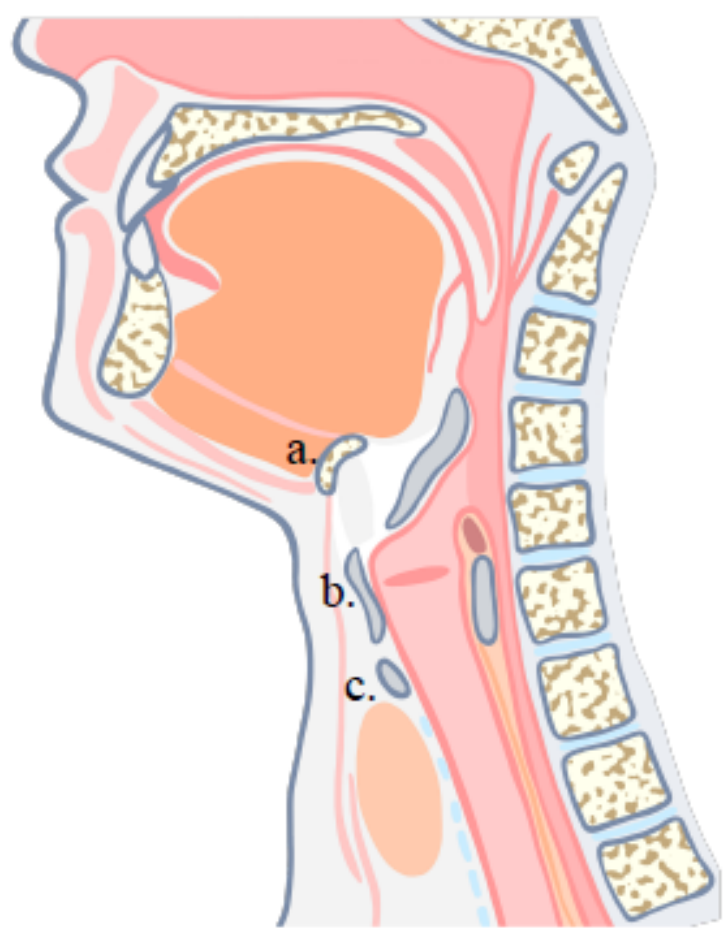

Figure 1 
Illustration of the anatomical features around the cervical spine. A: Illustration focusing on bones around cervical spine at C5/6. B: Illustrations focusing on soft tissues. a: hyoid bone, b: thyroid cartilage, c: cricoid cartilage.

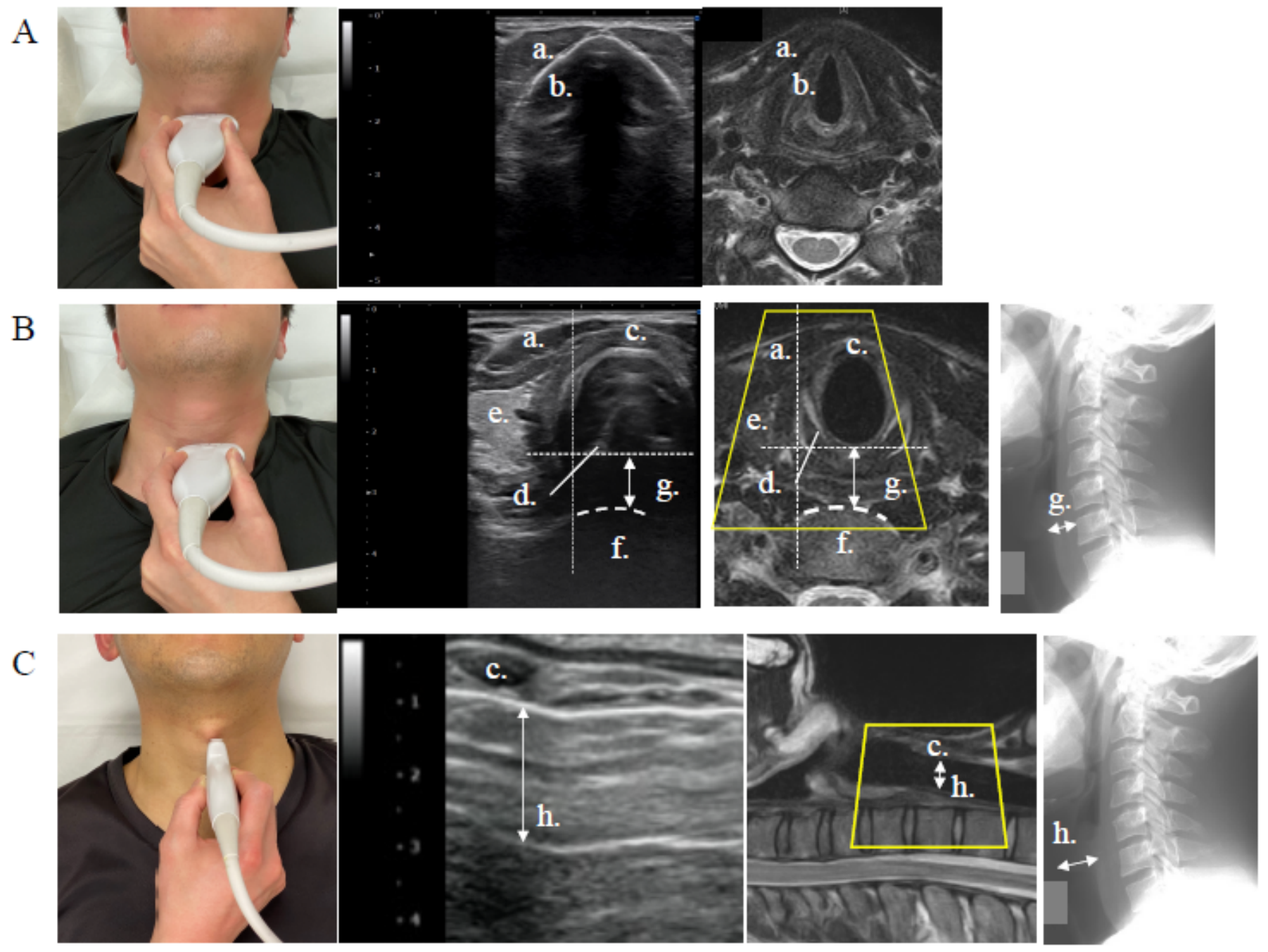

\section{Figure 2}

Macro photograph, ultrasound image, and magnetic resonance image A, B: Thyroid cartilage and cricoid cartilage in the transverse plane. C: Cricoid cartilage and tracheal cartilage in the longitudinal plane a: sternohyoid muscle, b: thyroid cartilage, c: cricoid cartilage, d; arytenoid cartilage, e: thyroid gland, f: C6 vertebral body, g: the thickness of the prevertebral soft tissue, h: upper airway 

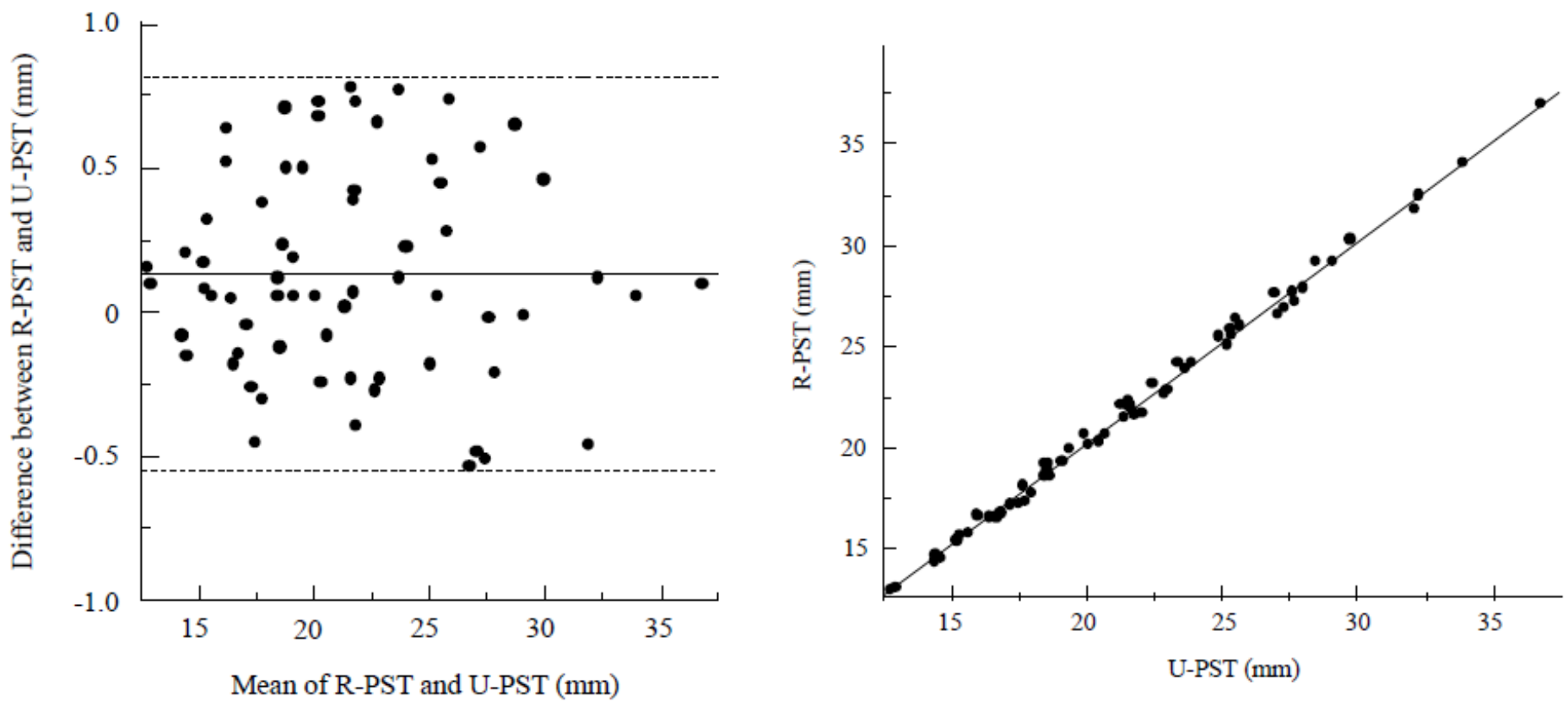

Figure 3

Statistical analysis results of the pilot study A: A Bland-Altman plot for mean thickness of prevertebral soft tissue (PST) obtained using radiography versus ultrasonography. B: Relationship of thickness of PST obtained using radiography versus ultrasonography $(r=0.9, p<0.0001)$.

Day 0

A

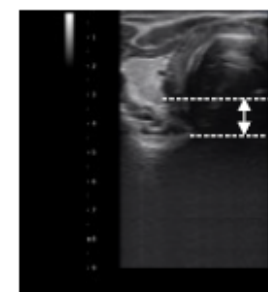

B

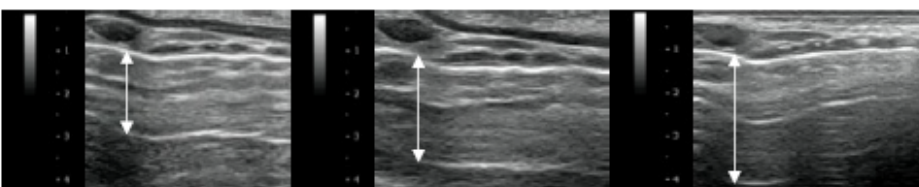

$\mathrm{C}$

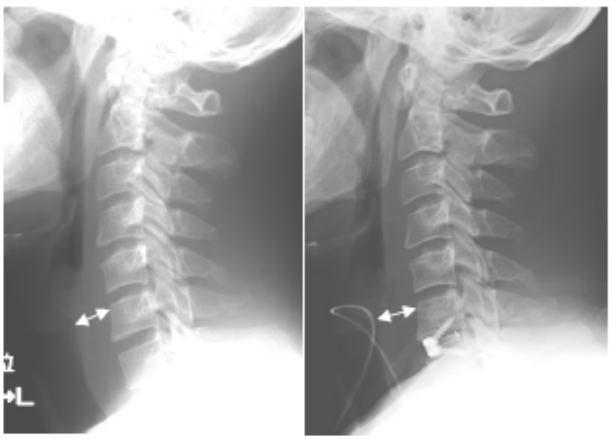

Day 3
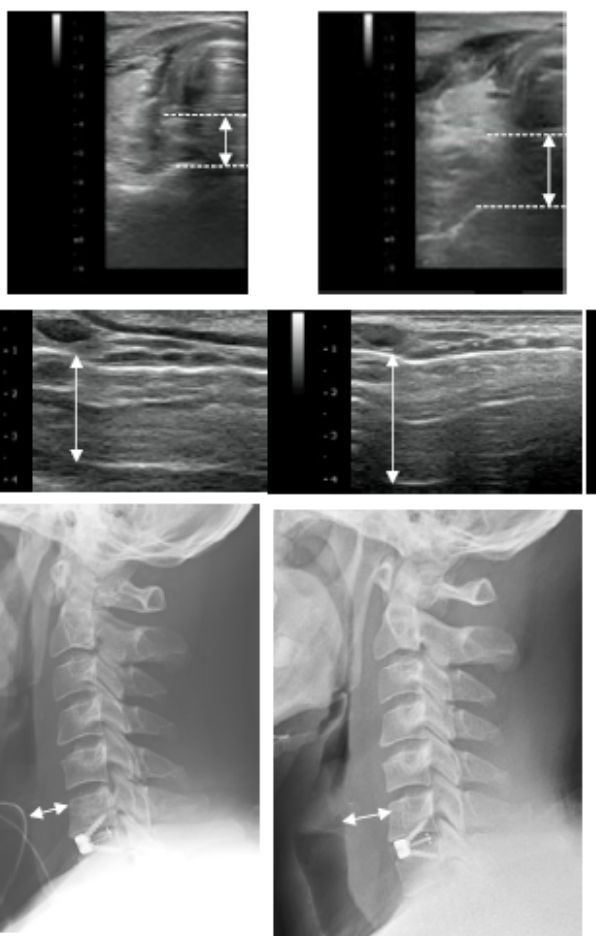

Day 5
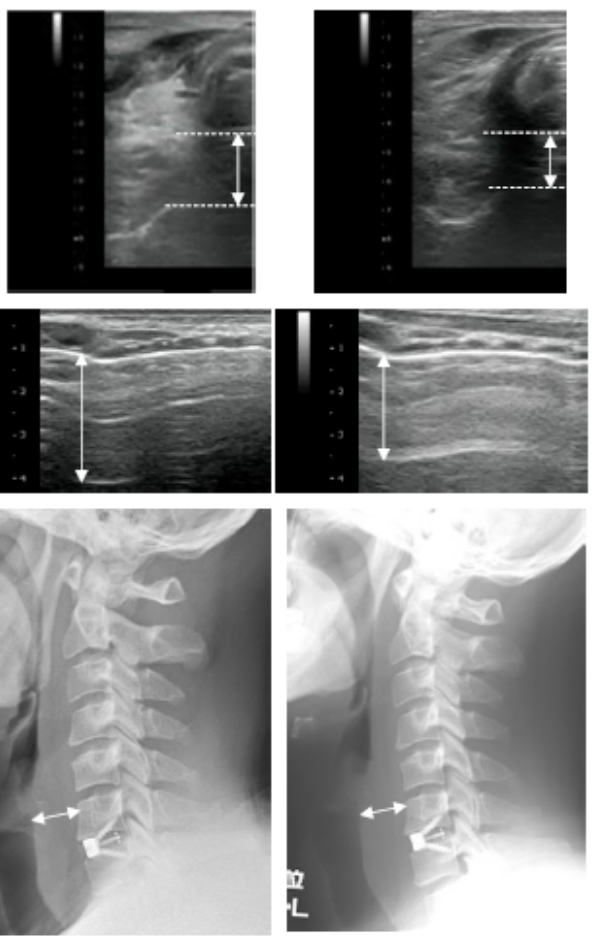

Day 7
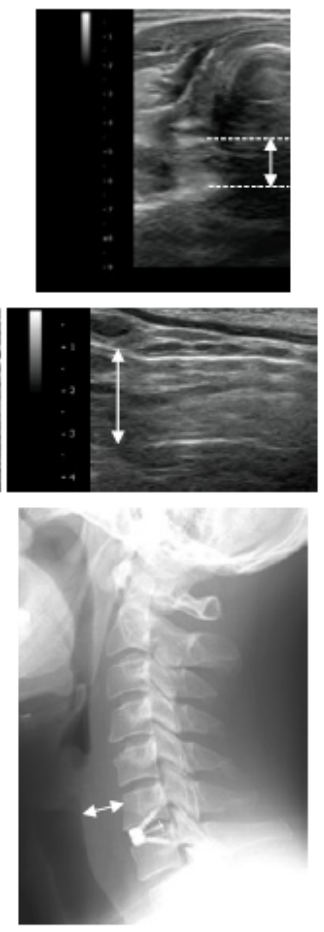

Day 14
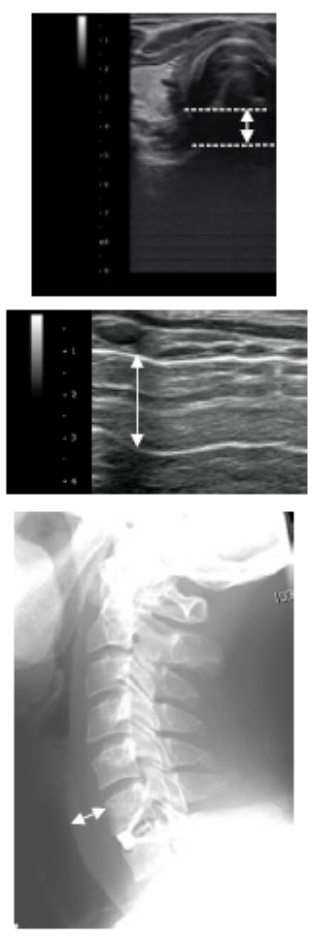
Figure 4

Postoperative course of the PST and upper airway in the representative case. A: Postoperative changes in the thickness of the PST measured via ultrasonography. B: Postoperative changes in the upper airway measured via ultrasonography. C: Postoperative changes in the thickness of the PST measured via lateral radiography of the cervical spine.
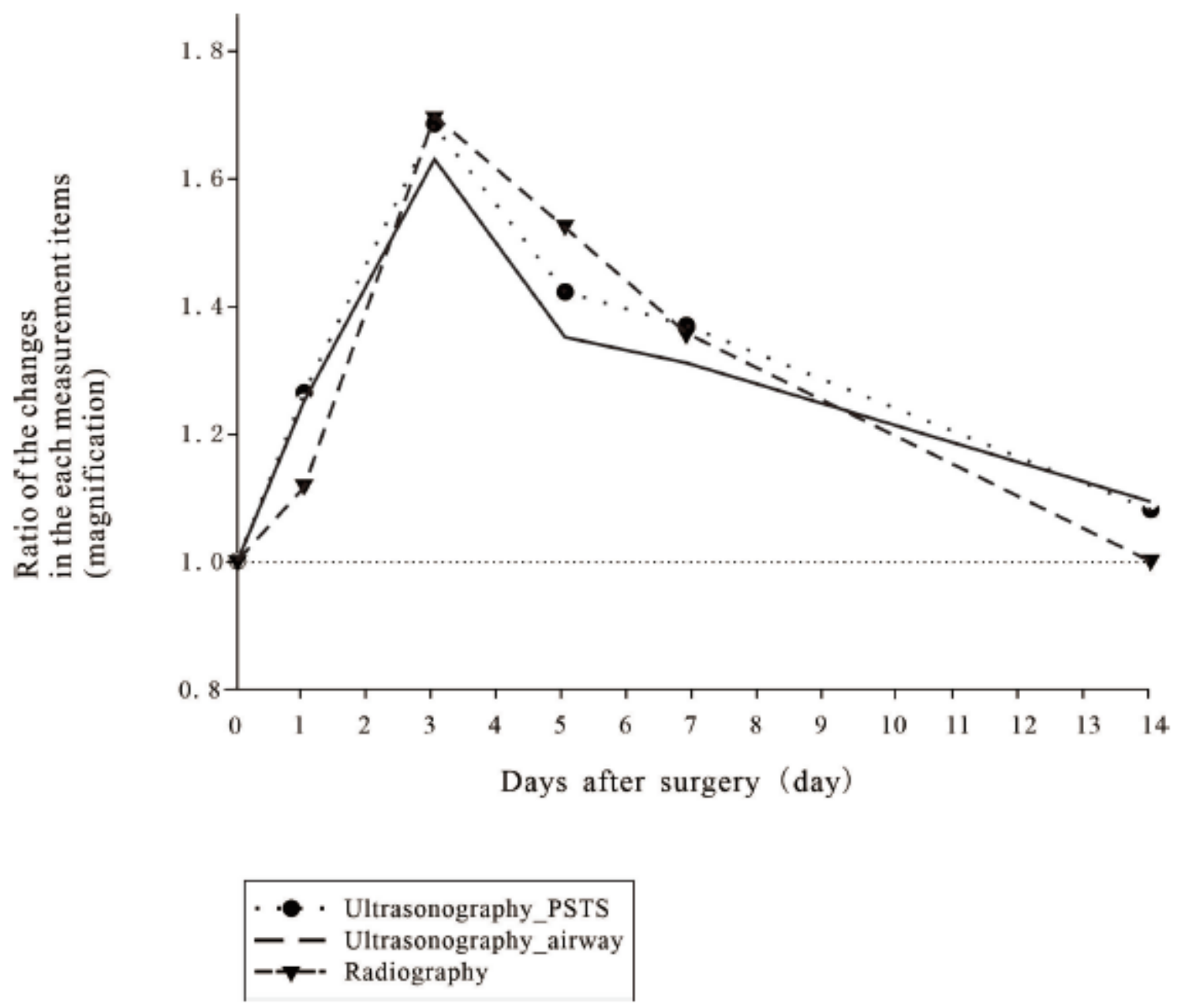

Figure 5

Summary of the information presented in Figure 4. It can be seen that ultrasonography (upper airway) or both lateral radiography of the cervical spine and ultrasonography (PST) had a very similar course. 